\title{
Emerging and re-emerging rickettsioses: endothelial cell infection and early disease events
}

\section{David H. Walker and Nahed Ismail}

Abstract | Rickettsiae cause some of the most severe human infections, including epidemic typhus and Rocky Mountain spotted fever. Substantial progress has been made in research into the genomics, vector relationships, pathogenesis and immunity of these obligate, intracellular, arthropod-transmitted bacteria. This Review summarizes our understanding of the early and late events in pathogenesis and immunity, modulation of the host response to rickettsial infection by the vector, host defence, virulence mechanisms and rickettsial manipulation of host cells.

Housekeeping gene A gene that is involved in the basic functions that are required for normal cell metabolism and is constitutively expressed

\section{Hypovolaemia} Decreased blood volume more specifically, a decrease in the volume of blood plasma.

Hypotensive shock Shock in which blood pressure is lower than normal and does not supply blood to the organs.

Department of Pathology, University of Texas, Medical Branch, Galveston, 77555-0609 Texas, USA. Correspondence to D.H.W. e-mail:dwalker@utmb.edu doi:10.1038/nrmicro1866
Pathogenic members of the Rickettsia genus are Gramnegative, obligate, intracellular bacteria that have a life cycle which involves both an arthropod vector and a vertebrate host ${ }^{1-3}$ (FIG. 1). Rickettsiae are classified into four groups based on their biological, genetic and antigenic characteristics ${ }^{4}$ : the spotted fever group (SFG), typhus group, transitional group and ancestral group. SFG rickettsiae include highly pathogenic organisms, such as tick-transmitted Rickettsia rickettsii (Rocky Mountain spotted fever (RMSF) $)^{5,6}$, Rickettsia conorii (Mediterranean spotted fever) ${ }^{1,2,7}$, Rickettsia africae (African tick-bite fever) ${ }^{8,9}$, Rickettsia parkeri (mildto-moderate spotted fever rickettsiosis, found in North and South America) ${ }^{10,11}$, Rickettsia slovaca

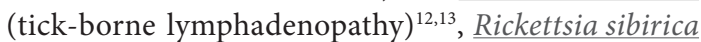
(North Asian tick typhus and lymphangitis-associated rickettsiosis) ${ }^{14}$, Rickettsia honei (found in Australia and Southeast Asia) ${ }^{15}$, Rickettsia japonica (found in Japan and Korea) ${ }^{16,17}$ and the apparently harmless Rickettsia montanensis, Rickettsia peacockii and Rickettsia rhipicephali ${ }^{2,18,19}$. The typhus group includes the highly pathogenic Rickettsia prowazekii (epidemic typhus) and Rickettsia typhi (murine typhus) ${ }^{20-23}$. The ancestral group includes Rickettsia bellii ${ }^{24}$ and Rickettsia canadensis ${ }^{25}$; whether these species are pathogens is unknown. The transitional group comprises Rickettsia akari (rickettsialpox) ${ }^{26}$, Rickettsia australis (Queensland tick typhus) ${ }^{27}$ and Rickettsia felis (flea-borne spotted fever) ${ }^{28}$ (TABLE 1). Rickettsia phylogeny has been addressed by sequence analyses of different genes, varying from housekeeping genes, which are useful for distinguishing distinct strains, to genes that are under evolutionary pressure, such as those that encode variable immunodominant outermembrane proteins. This phylogenetic analysis has substantially affected the proposed taxonomy of rickettsiae. However, rickettsial taxonomy remains a controversial subject, owing to the absence of a universal consensus on those criteria that should be used for the designation of species (BOX 1).

Rickettsiosis can present with an array of clinical signs and symptoms ${ }^{6-9,11-16,29-31}$. Highly lethal RMSF ${ }^{29,30,32,33}$ is characterized by headache, fever, myalgia, nausea and vomiting early in the illness; however, if untreated, severe injury can develop that sometimes progress to multi-organ failure. Systemic vascular infection in RMSF results in encephalitis, which leads to stupor, coma and seizures, interstitial pneumonia, non-cardiogenic pulmonary oedema and adult respiratory distress syndrome. In severe cases, hypovolaemia and hypotensive shock result in acute renal failure. Infection of a network of endothelial cells at the site of tick or mite inoculation of most SFG rickettsiae is followed by local dermal and epidermal necrosis that forms an eschar ${ }^{31}$. Disseminated infection, further injury to the vascular endothelium and infiltration of perivascular mononuclear cells leads to vasodilation, an increase in fluid leakage into the interstitial space and a characteristic rash. Epidemic typhus, which moulded world history for five centuries, is characterized by fever, headaches, mental confusion and a $\operatorname{rash}^{22,34}$ (BOX 2). Similar to RMSF, epidemic typhus can develop into life-threatening conditions in previously healthy, immunocompetent individuals, unless they are treated early with an appropriate antibiotic. However, unlike RMSF, $R$. prowazekii causes latent infection in 


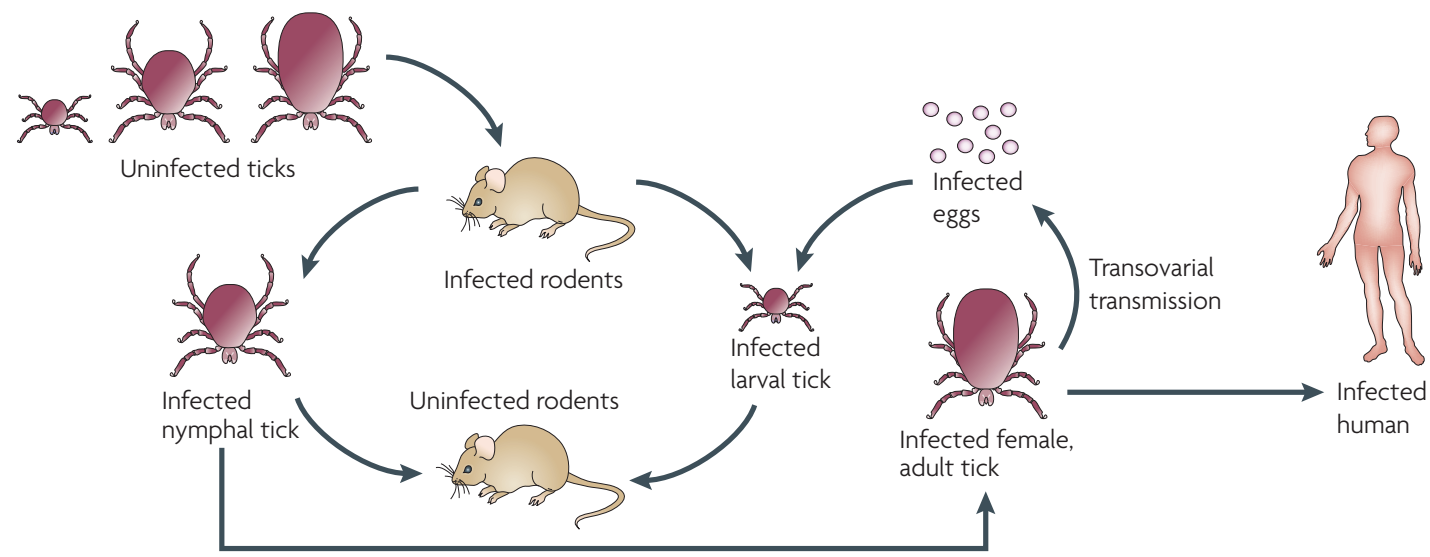

Tick moults; trans-stadial maintenance

Figure 1 | The life cycle of tick-borne rickettsiae. Spotted-fever-group rickettsiae are maintained in nature by transovarial and trans-stadial transmission in ticks and horizontal transmission to uninfected ticks that feed on rickettsemic rodents and other animals.

convalescent individuals, and recrudescence of latent $R$. prowazekii infection results in Brill-Zinsser disease, which is characterized by fever, rash and less-severe illness that nevertheless can infect feeding lice and ignite an epidemic ${ }^{35,36}$.

Interest in the pathogenesis of $R$. prowazekii and $R$. rickettsii has increased following their classification as select agents and as category B and C agents of potential bioterrorism, respectively, by the United States Centers for Disease Control and Prevention ${ }^{37}$ (see Further information). These pathogens are highly infectious agents that are easily disseminated and cause high morbidity and fatal disease, and thus require specific improvement in diagnostic tests and disease surveillance ${ }^{1,6}$ - the use of $R$. prowazekii as a biological weapon was initiated by the Soviet Union in the 1930s and Japan during the Second World War ${ }^{21,38}$.

The body of knowledge of rickettsial pathogenesis and immunity is based on disseminated infection of endothelial cells, the principal target host cells for rickettsiae. Human infections have rarely been investigated until the middle or late, and often fatal, stages of the illness. The best animal models for SFG rickettsioses use $R$. conorii and $R$. australis or typhus group rickettsiosis (using R. typhi) in susceptible mice that are inoculated intravenously: these manifest systemic endothelial-cell infection and characteristic pulmonary and cerebral lesions that recapitulate the clinical and pathological manifestations of the disease in humans. Infections of guinea pigs with $R$. rickettsii and $R$. prowazekii provide models of RMSF and epidemic typhus, respectively.

This Review highlights how the arthropod host acquires, maintains and transmits rickettsiae, the initial steps in pathogenesis and the subsequent interaction of the bacteria with cells in the endothelium, the main target cells. These events include: rickettsial entry, phagosomal escape, actin-based motility, cell-to-cell spread and the induction of cell injury. Regarding the host immune response to rickettsial infection, we will address innate and acquired immunity, with emphasis on recent data that illustrate the interaction of rickettsiae with dendritic cells (DCs). We also highlight some of the potential immunomodulatory effects of tick saliva on host defences and the immune response against Rickettsia spp.

Acquisition, interference and immunomodulation Acquisition. Vertebrate hosts are infected with rickettsiae via direct inoculation by a feeding tick or mite or by scratching infected louse or flea faeces into their skin. Ticks with hard exoskeletal chitin are vectors and reservoirs for SFG rickettsiae. The principal vectors of RMSF in the United States are Dermacentor variabilis and Dermacentor andersoni (TABLE 1), which are most active during the late spring and summer, when RMSF peaks. Epidemic typhus (BOX 2) caused by $R$. prowazekii is associated with cold weather and lack of hygiene ${ }^{22}$, and has re-emerged in louse-infested populations. Humans in endemic regions, as well as the eastern flying squirrel Glaucomys volans volans ${ }^{20,39}$, and its flea and louse in the United States, and ticks in Mexico and Africa are the known reservoirs of $R$. prowazekii ${ }^{40,41}$.

Interference. Infection of a tick with one SFG rickettsial species seems to interfere with infection by a second SFG rickettsial species. It was suggested that rickettsial infection of tick ovaries might alter the molecular-expression profiles of the oocytes and cause interference or blocking of the second infection ${ }^{42,43}$. This process of rickettsial 'interference' might affect the frequency and distribution of different pathogenic rickettsiae, and could explain the limited distribution of virulent $R$. rickettsii in the eastern part of the Bitterroot Valley, Montana, USA, where they infect less than $1 \%$ of wood ticks ${ }^{42,44}$. The low infection rate of $R$. rickettsii is attributed to the high infection rate of female wood ticks (D. andersoni) in the eastern, but not western, Bitterroot Valley with non-virulent rickettsiae, particularly R. peacockii (70\% in the eastern compared with $4 \%$ in the western side of Bitterroot Valley) ${ }^{19,44}$. In most 
Table 1 | Rickettsial diseases in humans

\begin{tabular}{|c|c|c|c|c|c|c|c|c|c|}
\hline Disease & Organism & $\begin{array}{l}\text { Arthropod } \\
\text { vector }\end{array}$ & Life cycle & $\begin{array}{l}\text { Geographic } \\
\text { area }\end{array}$ & Eschar & Rash & $\begin{array}{l}\text { Regional } \\
\text { lymph- } \\
\text { adenopathy }\end{array}$ & $\begin{array}{l}\text { Symptoms } \\
\text { or fever }\end{array}$ & $\begin{array}{l}\text { Mortality } \\
\text { rate }^{\star}\end{array}$ \\
\hline \multicolumn{10}{|c|}{ Tick-transmitted spotted fevers } \\
\hline $\begin{array}{l}\text { Boutonneuse } \\
\text { fever }\end{array}$ & $\begin{array}{l}\text { Rickettsia } \\
\text { conorii }\end{array}$ & $\begin{array}{l}\text { R. sanguineus and } \\
\text { Rhipicephalus } \\
\text { pumilio }\end{array}$ & $\begin{array}{l}\text { Transovarian } \\
\text { in ticks }\end{array}$ & $\begin{array}{l}\text { Southern } \\
\text { Europe, } \\
\text { Africa and } \\
\text { southern } \\
\text { Asia }\end{array}$ & Frequent & $\begin{array}{l}\text { Maculo- } \\
\text { papular }\end{array}$ & No & Yes & $\begin{array}{l}\text { Mild to } \\
\text { moderate }\end{array}$ \\
\hline $\begin{array}{l}\text { Maculatum } \\
\text { disease }\end{array}$ & $\begin{array}{l}\text { Rickettsia } \\
\text { parkeri }\end{array}$ & $\begin{array}{l}\text { Amblyomma } \\
\text { maculatum and } \\
\text { Amblyomma } \\
\text { triste }\end{array}$ & Ticks & $\begin{array}{l}\text { Western } \\
\text { hemisphere }\end{array}$ & Yes & Often & Yes & Yes & $\begin{array}{l}\text { None } \\
\text { reported }\end{array}$ \\
\hline \multicolumn{10}{|c|}{ Flea-transmitted diseases } \\
\hline $\begin{array}{l}\text { Flea-borne } \\
\text { spotted fever }\end{array}$ & $\begin{array}{l}\text { Rickettsia } \\
\text { felis }\end{array}$ & $\begin{array}{l}\text { Ctenocephalides } \\
\text { felis }\end{array}$ & $\begin{array}{l}\text { Transovarian } \\
\text { in the cat flea }\end{array}$ & Worldwide & Sometimes & Sometimes & No & Yes & $\begin{array}{l}\text { None } \\
\text { reported }\end{array}$ \\
\hline $\begin{array}{l}\text { Murine } \\
\text { typhus }\end{array}$ & $\begin{array}{l}\text { Rickettsia } \\
\text { typhi }\end{array}$ & $\begin{array}{l}\text { Xenopsylla } \\
\text { cheopis and } \\
\text { Ctenocephalides } \\
\text { felis }\end{array}$ & $\begin{array}{l}\text { Rat-flea for } \\
X . \text { cheopis } \\
\text { and } \\
\text { Opossumflea } \\
\text { for C.felis }\end{array}$ & Worldwide & No & Yes & No & Yes & Low \\
\hline $\begin{array}{l}\text { Epidemic } \\
\text { typhus }\end{array}$ & R. prowazekii & $\begin{array}{l}\text { Fleas and lice of } \\
\text { flying squirrels } \\
\text { and Glaucomys } \\
\text { volans volans }\end{array}$ & $\begin{array}{l}\text { Flying- } \\
\text { squirrel flea } \\
\text { and louse } \\
\text { ectoparasite }\end{array}$ & $\begin{array}{l}\text { United } \\
\text { States }\end{array}$ & No & Yes & No & Yes & Low \\
\hline \multicolumn{10}{|c|}{ Mite-transmitted diseases } \\
\hline Rickettsialpox & $\begin{array}{l}\text { Rickettsia } \\
\text { akari }\end{array}$ & $\begin{array}{l}\text { Liponyssoides } \\
\text { sanguinus }\end{array}$ & $\begin{array}{l}\text { Transovarian } \\
\text { in mites }\end{array}$ & Worldwide & Yes & Yes & Yes & Yes & $\begin{array}{l}\text { None } \\
\text { reported }\end{array}$ \\
\hline
\end{tabular}

*High mortality is $>15 \%$; moderate mortality is $7-15 \%$; mild-to-moderate mortality is $2-7 \%$ and low mortality is $\leq 1 \%$.

\section{Superinfection}

Infection by a microorganism

of a cell that is already infected

by another microorganism.

Transovarial

Passage of parasites or

infective agents from the

maternal body to eggs within

the ovaries and subsequently

to the larvae that hatch from

the eggs. geographic locations, fewer than $0.1 \%$ of Dermacentor spp. ticks carry $R$. rickettsii ${ }^{45}$. These data correspond to the focality of RMSF in the west side of the valley, where most human cases result from exposure to west-side ticks (D. andersoni). Unlike pathogenic R. rickettsii, which is lethal for ticks ${ }^{46}$ and highly virulent in guinea pigs $^{47}$, infection with $R$. peacockii does not cause a reduction in tick viability, and might even be beneficial for tick hosts by antagonizing superinfection of ovarian tissues by $R$. rickettsii.

Ticks acquire SFG rickettsial species through transovarial transmission (adult female to egg) and trans-stadial passage (egg to larva to nymph to adult), and by horizontal acquisition during feeding on a rickettsemic host. Most SFG rickettsiae are probably maintained in nature by all these mechanisms (FIG. 1). Therefore, the adverse effect of virulent $R$. rickettsii on the viability of adult ticks and maintenance of Rickettsia spp. in nature are probably balanced by the feeding of susceptible ticks on a rickettsemic host, which functions as an amplifying reservoir for rickettsiae. In fact, it has been shown that despite the high mortality of experimentally infected ticks, many larvae that acquire rickettsiae during feeding survive and are capable of transmitting the infection as 


\section{Box 1 | Rickettsial taxonomy}

Despite the major advances in serotyping and molecular genotyping of rickettsial isolates from defined geographic locations, Rickettsia taxonomy is still an evolving field. Novel Rickettsia isolates have been described in recent years, with the overenthusiastic designation of many new species, which vary much less from one another than the species of other bacterial genera ${ }^{107}$. The issue is not whether the isolates can be distinguished from one another, but rather whether the differences merit designation at the taxonomic level of species or even subspecies. Historically, different species of prokaryotic pathogens were defined based on the diseases that they caused, regardless of other ecological or evolutionary considerations. However, the clinical manifestations of most rickettsioses are neither specific to a particular agent nor to a geographic distribution. Thus, a consensus of taxonomic criteria has yet to be achieved for Rickettsia. A proposal to adopt the genetic-diversity limits of previously named Rickettsia species for several convenient, but not uniformly appropriate, genes is an approach that has been specifically rejected by experts in prokaryotic taxonomy ${ }^{108}$. In our opinion, if the classification of Rickettsia were congruent with other intracellular bacteria, many of the current species names would be designated as subspecies and scientists would recognize important new isolates as distinct strains without needing a new species name.

nymphs. This suggests that nymphs are a crucial link for $R$. rickettsii maintenance and transmission between vertebrates. Importantly, colonies of $R$. rickettsii-infected ticks have been observed to maintain the infection without overt deleterious effects for several generations. The pathological effect of rickettsiae on ticks would explain the occurrence of RMSF in endemic regions, despite the low prevalence of naturally infected adult ticks ${ }^{45,46}$.

Immune modulation. Studies of the virulence of rickettsiae within their tick vector revealed that feeding ticks or incubating them at $37^{\circ} \mathrm{C}$ for $24-48$ hours before their inoculation onto non-immune guinea pigs results in severe disease, compared with asymptomatic infection following inoculation of guinea pigs with infected ticks that were maintained at $4^{\circ} \mathrm{C}$ or starved for a prolonged period $^{48}$. This observation, described as the reactivation phenomenon by Parker and Spencer ${ }^{44}$, refers to changes in the virulence of rickettsiae that are linked to the physiological status of the ticks.

As an immune evasion or modulation mechanism that allows the ticks to feed for several days or weeks, ticks inoculate their saliva with anti-haemostatic components that are crucial for the enhancement of blood feeding and salivary immunomodulatory components that enhance pathogen transmission and prevent the host from rejecting the ticks ${ }^{49-53}$. For example, the saliva of ticks inhibits neutrophil function ${ }^{52}$, interferes with the complement system ${ }^{49-51}$, natural killer (NK) cell and macrophage activity ${ }^{54}$, decreases the production of cytokines, such as interleukin-12 (IL-12) and interferon- $\gamma$ (IFN- $\gamma$ ), and decreases T-cell proliferation ${ }^{55,56}$. Tick-infested mice do not develop resistance to further infestations with Rhipicephalus sanguineus, and the immune response in infested mice exhibits a T helper $2\left(\mathrm{~T}_{\mathrm{H}} 2\right)$-type pattern ${ }^{56,57}$. Tick saliva might influence T-cell-effector functions through its initial interaction with professional antigenpresenting cells, namely DCs ${ }^{58}$. Such initial interactions can subsequently influence the differentiation towards either a $\mathrm{T}_{\mathrm{H}}$ 2-cell phenotype (an ineffective acquired immune response against intracellular pathogens such as Rickettsia spp.) or an immunosuppressive phenotype ${ }^{58,59}$. Indeed, the addition of tick saliva to bone-marrowderived DCs inhibits their maturation by decreasing the expression of co-stimulatory (CD40, CD80 and CD86) and adhesion (CD54) molecules ${ }^{58,59}$. Furthermore, the maturation of DCs that is stimulated by lipopolysaccharide in the presence of tick saliva results in reduced expression of co-stimulatory molecules and reduced production of IL-12, but not immunosuppressive IL-10. More importantly, DCs cultured with tick saliva are inefficient in the induction and activation of antigenspecific, cytokine-producing $\mathrm{T}$ cells ${ }^{58,59}$. As discussed below, fully mature DCs are crucial for induction of an effective $\mathrm{T}_{\mathrm{H}} 1$ response against Rickettsia spp. Therefore, it is possible that suppression of DC maturation by tick saliva during the initial stages of rickettsial infection could interfere with their co-stimulatory and antigenpresentation functions. Such suppression of DC maturation would adversely influence the acquired immune response against tick-transmitted Rickettsia spp., thereby leading to increased host susceptibility to severe and fatal rickettsial disease. However, because the tick host is an important component in the life cycle of rickettsiae, further studies are required to address important questions related to vector biology and disease pathogenesis, such as whether tick saliva enhances Rickettsia spp. infectivity during natural transmission and whether pre-exposure to saliva from uninfected ticks that generates immunity to saliva protects the vertebrate host, particularly in endemic areas, from natural tick-transmitted rickettsial infection. If immunity to salivary components can

\section{Box 2 | Epidemic typhus}

Epidemic typhus determined the outcome of European wars from the sixteenth century to the twentieth century. In Russia, during the First World War, the revolution and its aftermath, 30 million people suffered from typhus fever and 3 million of them died. The first description of typhus originated from the siege of Naples in 1528, but the role of the human body louse as a vector was not recognized until 1909 , for which Charles Nicolle was awarded a Nobel Prize. Among the enigmas of typhus, two of the most intriguing questions are: in what cells and organs of the body does latent Rickettsia prowazekii reside during the period after recovery from the acute infection; and what factors and mechanisms are responsible for the reactivation of infection that leads to rickettsemia and potential louse-borne spread of another epidemic? 
a

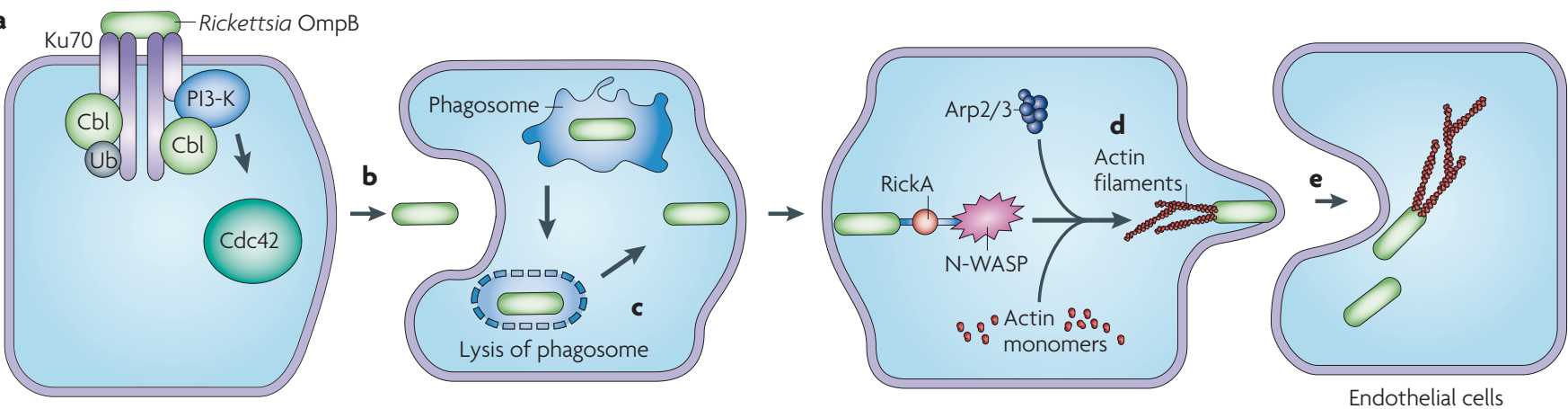

Figure 2 | Host cell interactions of rickettsiae. a | Spotted-fever-group rickettsiae attach to Ku70 on the surface of human target cells (the endothelium) via outer-membrane-protein B (OmpB) and to an unknown receptor via outermembrane-protein A. b |Cbl ubiquitinates Ku70 (REF. 61), and signal-transduction events that involve Cdc42, protein tyrosine kinase, phosphatidylinositol 3'-kinase (PI3-K) and Src-family kinases activate the Arp 2/3 complex to induce cytoskeletal actin to phagocytose the rickettsia ${ }^{62} . \mathbf{c} \mid$ Membranolytic phospholipase D and haemolysin C mediate rickettsial phagosomal escape ${ }^{83}$. d | RickA-stimulated activation of Arp2/3-mediated polymerization of host actin propels the bacterium through the cytosol and into filopodia. e | Rickettsiae are then either released from filopodia extracellularly or spread into the adjacent cell ${ }^{84-88}$. Cbl, family of ubiquitin ligases; N-WASP, neural Wiskott-Aldrich syndrome protein; Ub, ubiquitin.

protect against natural rickettsial infection, an effective anti-rickettsial vaccine could be designed that contains tick salivary proteins that act as an adjuvant with specific rickettsial antigens.

\section{Rickettsia-endothelial cell interactions}

Rickettsial entry. $R$. conorii $\mathrm{OmpB}$ binds specifically to Ku70 (FIG. 2), a component of the DNA-dependent protein kinase ${ }^{60}$. The binding and recruitment of Ku70 to the plasma membrane are important events in the entry of $R$. conorii into non-phagocytic mammalian cells ${ }^{60}$. Although nuclear Ku70 is translocated to the cytoplasm and plasma membrane, where it inhibits apoptosis and mediates homologous and heterologous cell adhesion and fibronectin binding, it has been proposed that the presence of Ku70 within lipid rafts might have an important role in the signal transduction that leads to induced phagocytosis. The role of cholesterol as an essential component of the membrane receptor that binds to $R$. prowazekii was described previously ${ }^{61}$. Similar to other intracellular pathogens, such as Listeria monocytogenes, the entry of $R$. conorii into non-phagocytic cells is dependent on membrane cholesterol. Ku70 is present within lipid microdomains that are enriched in lipid-raft components. The association of Ku70 with lipid microdomains and its binding to $R$. conorii suggest that Ku70 has an important role in cholesterol-dependent bacterial entry $^{60}$. Although the exact mechanism by which Ku70 supports the entry of $R$. conorii into non-phagocytic cells remains unclear, the binding of $R$. conorii $\mathrm{OmpB}$ to $\mathrm{Ku} 70$ might activate membrane Ku70, which is postulated to lead to the activation of a cascade of signalling events, including the small GTPase, Cdc42, phosphoinositidyl3-kinase, $s r c$-family tyrosine kinases and the tyrosine phosphorylation of focal adhesion kinase ${ }^{62}$. These signalling events are known to be strongly associated with $\beta 1$-integrin activation and bacterial entry ${ }^{63}$ (FIG. 2). Similar to the entry of L. monocytogenes into its host cells, $R$. conorii infection stimulates the ubiquitination of Ku70. In addition, the ubiquitin ligase $\mathrm{c}-\mathrm{Cbl}$ is recruited to $R$. conorii-entry foci, and downregulation of endogenous c-Cbl blocks bacterial invasion and Ku70 ubiquitination ${ }^{60,62}$. The binding of Ku70 to OmpB and the role of Ku70 in bacterial entry into host cells correlate with the decreased expression of OmpB that is associated with reduced virulence of $\underline{R}$. rickettsii str. Iowa $^{64}$ and the observation that anti-OmpB antibodies protect animals from an otherwise lethal challenge of R. conorii ${ }^{6-67}$. However, it is possible that SFG rickettsial OmpA or other unidentified rickettsial outermembrane proteins also mediate adhesion by binding to unknown receptors ${ }^{68}$.

Rickettsial diseases and endothelial pathogenesis. Most of the clinical characteristics of rickettsial diseases are attributed to disseminated infection of the endothelium, where they grow and stimulate oxidative stress, thereby causing injury to the endothelial cells. Severe morbidity and mortality of RMSF are due to effects such as cerebral oedema and non-cardiogenic pulmonary oedema. The most prominent pathophysiological effects of rickettsial infection of endothelial cells include: an increase in vascular permeability; generalized vascular inflammation; oedema; increased leukocyte-endothelium interactions; and release of powerful vasoactive mediators that promote coagulation and pro-inflammatory cytokines ${ }^{69,70}$. Evidence that supports a pro-coagulant and pro-inflammatory phenotype of the host response is provided by studies of cultured endothelial cells in which rickettsial infection causes increased expression of tissue factor, thrombomodulin plasminogen-activator inhibitor 1 , IL-1, IL-6, IL-8 and E-selectin ${ }^{70-73}$. Increased plasma levels of von Willebrand factor that are associated with increased levels of inflammatory cytokines, such as IL-6, have also been detected in patients with African tick-bite fever and Mediterranean spotted fever ${ }^{69,74}$. Prostaglandins and leukotrienes are crucial vasoactive modulators of vascular tone and permeability that are potential mediators
Causes constriction or dilation of blood vessels. 
of microvascular injury and vasculitis in rickettsial infection ${ }^{75,76}$. These vasoactive substances are generally generated by an inducible isoenzyme cyclooxygenase $(\mathrm{COX})^{75}$. Transcriptional activation of host endothelial cells in response to stimulation with $R$. rickettsii or $R$. conorii involves rapid regulation of COX2 expression and inhibition of COX2 activity during infection, which leads to decreased levels of secreted prostaglandins. As a regulatory mechanism that prevents the development of extensive vascular injury, endothelial cells that are infected with $R$. rickettsii produce haem oxygenase, an antioxidant, anti-inflammatory and vasoprotective enzyme that controls COX2 activity ${ }^{77}$. The production of this antioxidant mechanism by $R$. rickettsii-infected cells seems to be dependent on several factors, including: dose and kinetics of rickettsial infection; viability of the host cells; de novo protein synthesis by host cells; adhesion and entry of Rickettsia spp. to the host cell membrane; rickettsial replication; and viability ${ }^{77}$. Viability is probably influenced by the host immune status, as well as whether patients are treated with doxycycline at an early stage of infection. Nevertheless, the balance between the production of vasoprotective, anti-inflammatory and antioxidant haem oxygenase and the generation of vasoactive substances by COX2 in Rickettsia-infected endothelial cells might determine the outcome of rickettsial infection and thus the susceptibility or resistance to severe, and sometimes fatal, disease.

In an in vitro model of human microvascular endothelium, $R$. rickettsii causes early-dose-dependent increased vascular permeability. Furthermore, proinflammatory cytokines, such as IL-1 $\beta$ and tumour necrosis factor (TNF), which are probably produced in vivo by perivascular $\mathrm{T}$ lymphocytes and macrophages, cause a further enhancement of vascular permeability that is not dependent on nitric oxide production ${ }^{78}$. Increased permeability of endothelial monolayers that are infected with $R$. rickettsii in the presence of proinflammatory cytokines is associated with disruption of intercellular adherens junctions and redistribution of p120 and $\beta$-catenin proteins - these proteins attach the endothelial cells to the extracellular matrix and regulate the functional interaction of vascular endothelial (VE)cadherin with the actin cytoskeleton - from the cell-cell junction by a nitric-oxide-independent mechanism. The cellular and molecular mechanism by which rickettsiae directly increase endothelial permeability is not yet clear. $R$. rickettsii-infected human-derived microvascular endothelial cells produce nitric oxide, which has been shown to play a part in increasing vascular permeability during rickettsial infection. However, blocking nitric oxide production does not influence endothelial-cell monolayer integrity despite an increase in the number of intracellular rickettsiae. These data suggest that other downstream or upstream intracellular molecules produced by endothelial cells at early stages after infection cause increased vascular permeability. Possible effectors could include reactive oxygen species or vascular endothelial growth factor, which have been associated with vascular dysfunction in endothelial-cell infections that are caused by other pathogens.
Rickettsiae inhibit endothelial-cell apoptosis by a mechanism that involves nuclear factor- $\kappa \mathrm{B}(\mathrm{NF}-\kappa \mathrm{B})$ activation $^{79,80}$, an immune evasion strategy that enables rickettsiae to survive and replicate within the endothelium. NF- $\kappa B$ is a transcription factor that regulates many inflammatory genes that are involved in cytokine and chemokine production. The anti-apoptotic effect of rickettsiae on endothelial cells is linked to the pro-inflammatory phenotype of those cells. Lymphocyte adhesion to the endothelium is a crucial step for transmigration of lymphocytes to the areas of inflammation that are beneath the endothelium. The production of proinflammatory cytokines, such as IL- $1 \alpha$, IL- 6 and IL- 8 , by endothelial cells promotes the expression of endothelialcell adhesion molecules, such as intercellular-adhesion molecule 1 and vascular-cell-adhesion molecule 1 , which support the recruitment of T cells to the site of infection. Rickettsiae also enhance the expression of chemokine receptors, such as CXC-chemokine receptor 3, and the production of chemokines, such as CXC-chemokine ligand 9 (CXCL9; also known as MIG) and CXCL10 (also known as IP10), by infected endothelial cells ${ }^{81,82}$ (FIG. 3). The peak of expression of these chemokines correlates with maximal T-cell infiltration (mainly $\mathrm{CD} 8^{+} \mathrm{T}$ cells) at the site of infection ${ }^{82}$. However, it is not yet clear whether greater chemokine production and increased T-cell migration to the site of infection contribute more to the pathogenesis of severe disease or to protection against rickettsial infection.

Actin-dependent movement of rickettsiae. The entry of both SFG and typhus-group rickettsiae into mammalian cells is a dynamic process between metabolically active Rickettsia spp. and mammalian cells. Typhus-group rickettsiae enter the endothelial cells through adherence to undefined receptors and induced phagocytosis, followed by escape to the cytosol, which is mediated by phospholipase D and haemolysin $C^{83}$. Replication of $R$. prowazekii inside host cells is followed by the rupture of infected cells and release of rickettsiae, which infect neighbouring cells. Spotted-fever rickettsiae can manipulate host cell signalling and endocytic pathways to their advantage, similar to L. monocytogenes ${ }^{84}$. SFG Rickettsia spp. harness the actin-polymerization machinery in the cytoplasm to facilitate intracellular and intercellular movement. After invasion of the host and entry into the cytosol, most SFG rickettsiae are propelled by polymerization of the host cell cytoskeletal protein actin at the surface of one pole of the rickettsiae. Unlike Listeria spp. and Shigella spp., which also escape into the cytosol, the actin tails of Rickettsia spp. are much less dense and comprise several distinct bundles of long, unbranched filaments that are similar to those present in filopodia ${ }^{85,86}$. The spread of Rickettsia spp. from cell to cell enables rickettsiae to avoid contact with immune-cells and antibodies, which could be a possible immune-evasion mechanism. A comparison of the complete genome sequence of $R$. conorii with that of typhus group $R$. prowazekii, which does not have actin tails and thus does not manifest an actin-based motility ${ }^{85}$, identified a $2 \mathrm{~kb} R$. conorii-specific region that encodes a predicted protein of 517 amino acids, known as RickA ${ }^{86}$. 


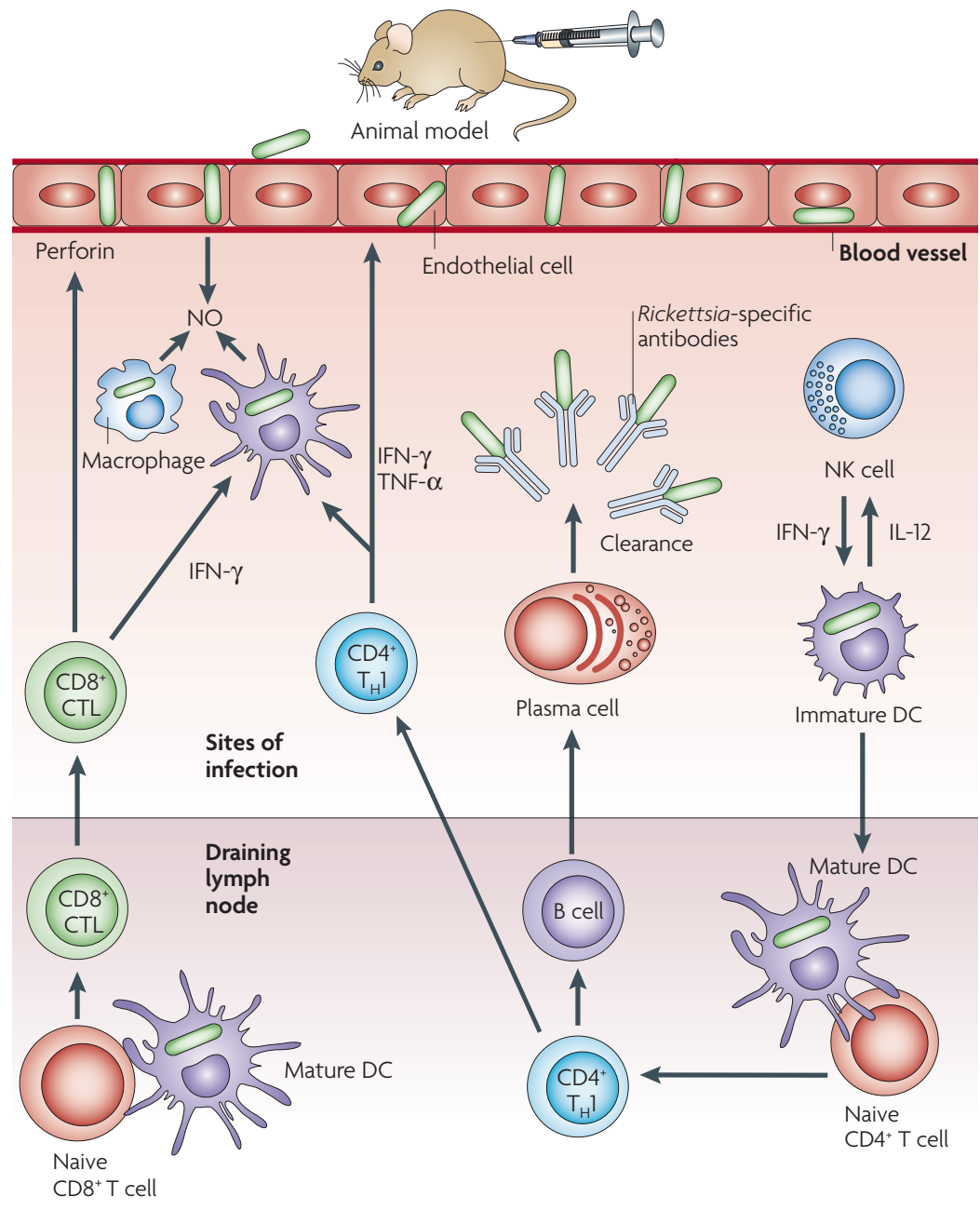

Figure 3 | Model of protective immunity in rickettsial infection. This hypothetical model is based on in vitro and in vivo studies in an animal model of mild disseminated spotted-fever rickettsiosis that was caused by sublethal rickettsial infection. Immature dendritic cells (DCs) that encounter rickettsiae in the peripheral tissues, such as skin and lung, undergo maturation and migrate to secondary lymphoid tissues (for example, draining lymph nodes), where they activate antigen-specific T lymphocytes. Rickettsial infection stimulates DC maturation (upregulation of the major histocompatibility complex and co-stimulatory molecules CD80, CD86 and CD40). Interferon- $\gamma($ IFN- $\gamma$ ) and tumour necrosis factor- $\alpha$ (TNF- $\alpha$ ), which are produced by other cells of the innate immune system, such as natural killer (NK) cells or infected endothelial cells, could promote complete DC maturation, which is marked by the production of interleukin-12 (IL-12). IL-12 activates NK cells, which are crucial for the early clearance of rickettsiae. Mature Rickettsia-infected DCs enter lymph nodes through afferent lymphatic vessels, where they display antigens to naive antigen-specific $\mathrm{CD} 4^{+}$and $\mathrm{CD} 8^{+} \mathrm{T}$ cells and provide co-stimulatory signals that activate antigen-specific $T$ cells. Activated antigen-specific $\mathrm{CD}^{+}$and $\mathrm{CD} 8^{+} \mathrm{T}$ cells proliferate and differentiate into antigen-specific effector-type- 1 cells that produce IFN- $\gamma$ and TNF- $\alpha$. Induction of $\mathrm{T}_{H} 1$ cells is mediated, in part, by IL-12 production by DCs. In addition, antigen-specific B cells proliferate and differentiate into antibody-secreting cells. Rickettsia-specific antibodies have an important role in protection against re-infection. These differentiated $B$ and $T$ lymphocytes migrate back to the blood and then to the site of infection, where they mediate the clearance of rickettsiae. Production of chemokines, such as CXC-chemokine ligand 9 (CXCL9) and CXCL10, by infected endothelial cells enhances lymphocyte migration. Production of IFN- $\gamma$ and TNF- $\alpha$ by $C D 4^{+} T_{H} 1$ effectors and $C D 8^{+}$cytotoxic T lymphocytes (CTLs) activates infected target cells, such as DCs, macrophages and endothelial cells. Activated infected cells kill rickettsiae by producing intracellular rickettsicidal molecules; for example, nitric oxide. Further clearance of rickettsial infection requires cytotoxic antigenspecific $C D 8^{+} T$ cells that eliminate Rickettsia-infected cells by a perforin-mediated mechanism.
RickA contains a central proline-rich domain and a carboxy-terminal WH2 (Wiskott-Aldrich syndrome protein (WASP) homology 2) domain ${ }^{87}$. WH2 binds to actin monomers, which is followed by binding to a region with homology to the central and acidic domain of WASP-family proteins, including an amphipathic helix that is predicted to bind the Arp2/3 complex $x^{87,88}$ (FIG. 2). Activation of Arp2/3 then results in nucleation of actin polymerization and induction of the formation of a network of long, unbranched filaments in Rickettsia spp. actin tails ${ }^{87}$. RickA proteins from R. conorii and R. rickettsii have a single $\mathrm{WH} 2$ domain that is similar to WASP, whereas $R$. montanensis RickA has two WH2 domains that are similar to neural-WASP. The exact role of RickA in intracellular motility, cell-to-cell spread and virulence of SFG rickettsiae has not been completely determined owing to a lack of genetic tools. However, lack of motility and virulence in $R$. peacockii, an SFG rickettsia that has a naturally occurring transposon insertion in rick $A$, indicates a possible role for RickA in the motility (and perhaps virulence) of SFG rickettsiae ${ }^{89}$ (TABLE 2).

\section{Host response to infection}

Innate immunity. Early resistance to infection is attributed to the production of IFN- $\gamma$ by NK cells and the resultant activation of infected target cells, principally endothelial cells, DCs and macrophages (FIG. 3). IFN- $\gamma$ and TNF are essential for primary defence against infection with Rickettsia spp., and mice that lack these cytokines develop an overwhelming infection and succumb to an ordinarily sublethal dose of rickettsiae $e^{90,91}$. Eschar lesions from patients with mild-to-moderate boutonneuse fever express high mRNA levels of TNF, IFN- $\gamma$, IL-10, RANTES, indoleamine-2,3-dioxygenase (an enzyme that is involved in limiting rickettsial growth by tryptophan degradation) and inducible nitric oxide synthase (a source of microbicidal nitric oxide) ${ }^{92}$. Significantly high levels of intralesional IL-10 are inversely correlated with low levels of IFN- $\gamma$ and TNF. Skin lesions from patients with severe BF express higher levels of RANTES than those with mild or moderate disease ${ }^{92}$. However, it is not clear whether these cytokine and chemokine responses in patients with BF are simply a correlate of mild and severe disease or contribute to anti-rickettsial immunity and pathogenesis.

At the cellular level, cytokine-activated endothelial cells and macrophages are the principal mediators of the killing of rickettsiae, as they are also the major target cells. Although the mechanisms of bacterial killing by recruited lymphocytes and inflammatory cells in vivo are not completely defined, the induction of nitric oxide (FIG. 3), oxidative burst, production of hydrogen peroxide and/or tryptophan degradation by endothelial cells and macrophages contribute to pathogen clearance in vitro $^{93}$.

Interaction of rickettsiae with dendritic cells. Although extensive studies have examined the acquired immune response against Rickettsia spp., there is still a large gap in our understanding of the initial interaction between tick-transmitted rickettsiae and host immune cells at the 
Table 2 | Candidate rickettsial virulence genes

\begin{tabular}{|c|c|c|}
\hline Rickettsial gene & Encoded product & Potential function \\
\hline pat1 & Patatin B1 precursor & Membranolytic phospholipase A host cell escape \\
\hline tlyA & Haemolysin A & Membranolytic traversal of host cell membrane \\
\hline pld $d^{118}$ & Phospholipase D & Membranolytic phagosomal escape \\
\hline $\operatorname{inv} A^{119,120}$ & Dinucleoside polyphosphate hydrolase & Hydrolysis of toxic dinucleoside polyphosphates to ATP \\
\hline $\operatorname{sod} B$ & Superoxide dismutase & Neutralizes oxidative stress of reactive oxygen species \\
\hline $\begin{array}{l}\text { Lipopolysaccharide } \\
\text { synthesis genes }\end{array}$ & Lipopolysaccharide & Endotoxin-mediated inflammation \\
\hline sca genes ${ }^{121,122}$ & $\begin{array}{l}\text { Surface cell antigens, except for sca4, which is an } \\
\text { intracellular protein }\end{array}$ & Autotransporter outer-membrane proteins \\
\hline rick $A^{87,88}$ & Actin-tail polymerization gene & $\begin{array}{l}\text { Formation of actin tail and mediation of intracellular and } \\
\text { intercellular rickettsial spread }\end{array}$ \\
\hline
\end{tabular}

site of inoculation (the dermis of the skin) and the effect of this interaction on the acquired immune response in secondary lymphoid organs. Transmission of rickettsiae through the dermis suggests that resident DCs might have an important role in innate and acquired immunity. Rickettsia spp. effectively infect bone-marrow-derived DCs (BMDCs). Compared with their immediate and exclusive cytoplasmic localization within endothelial cells, rickettsiae efficiently enter and localize in both phagosomes and the cytosol of BMDCs ${ }^{94}$. The dual intracellular localization of rickettsiae within BMDCs favours the access of rickettsial antigen to both major histocompatibility complex (MHC) class I and II pathways, thus promoting the activation of Rickettsia-specific $\mathrm{CD}^{+}$and $\mathrm{CD}^{+}{ }^{+} \mathrm{T}$ cells, respectively. Rickettsiae have been shown to induce the maturation of BMDCs, which results in the upregulation of CD40, CD80, CD86 and MHC-II and production of IL-2, IL-12p40 and IL-23 - IL-12p40 and IL-23 are prototypic $\mathrm{T}_{\mathrm{H}} 1$-promoting cytokines ${ }^{94}$. DCs efficiently present rickettsial antigens to $\mathrm{T}$ cells, as shown by the ability of $R$. conorii-infected DCs to effectively activate immune $\mathrm{CD} 4^{+}$and $\mathrm{CD} 8^{+}$ $T$ cells that were derived from $R$. conorii-infected mice and stimulate the $\mathrm{T}_{\mathrm{H}} 1$ response owing to the production of substantial quantities of IFN- $\gamma^{94,95}$ (FIG. 3). Interestingly, Rickettsia-infected DCs activate naive $\mathrm{CD}^{+} \mathrm{T}$ lymphocytes in vitro in the absence of $\mathrm{CD} 4^{+}$ T-cell help ${ }^{95}$ (FIG. 3) together with the induction of DC maturation by rickettsiae. Thus, Rickettsia-infected DCs provide signal 1 (TCR stimulation) and signal 2 (IL-2 and $\mathrm{T}_{\mathrm{H}} 1$ cytokines) to naive $\mathrm{T}$ cells, which accounts for their ability to induce activation and differentiation of T cells (FIG. 3). Interestingly, the transfer of rickettsiae-stimulated DCs protects mice from lethal rickettsial challenge by limiting rickettsial proliferation in vivo, whereas partial protection is observed in mice that receive LPS-stimulated $\mathrm{DC} \mathrm{s}^{95}$. Protection against $R$. conorii following the transfer of DCs is associated with the production of antigen-specific IFN- $\gamma$ by T cells and the expansion of NK cells.

The role of DCs in resistance and susceptibility to fatal SFG rickettsiosis has been investigated in susceptible $\mathrm{C} 3 \mathrm{H} / \mathrm{HeN}$ mice and highly resistant $\mathrm{C} 57 \mathrm{BL} / 6$ mice, which remain healthy after a dose of $R$. conorii that kills $100 \%$ of $\mathrm{C} 3 \mathrm{H} / \mathrm{HeN}$ mice ${ }^{94}$. Early effective bacterial elimination in C57BL/6 mice suggests that the crucial immune effectors that determine the resistance or susceptibility to fatal disease are determined by innate immune cells. BMDCs of resistant mice internalize greater quantities of rickettsiae, kill rickettsiae more effectively, express higher levels of MHC-II, produce more IL-12p40 and are more potent in priming naive IFN- $\gamma$ to produce $\mathrm{CD}^{+} \mathrm{T}_{\mathrm{H}} 1$ cells. By contrast, BMDCs of susceptible mice fail to induce $\mathrm{CD} 4^{+} \mathrm{T}$-cell activation and differentiation into the $\mathrm{T}_{\mathrm{H}} 1$ or $\mathrm{T}_{\mathrm{H}} 2$ phenotype in an in vitro co-culture system. The $\mathrm{CD}^{+} \mathrm{T}$-cell suppressive function of Rickettsia-infected BMDCs from susceptible mice is associated with the expansion of forkhead box P3 (Foxp3) ${ }^{+} \mathrm{CD} 4{ }^{+}$T-regulatory cells in an in vitro co-culture system ${ }^{94}$ (FIG. 4). These data suggest that rickettsiae stimulate DCs to develop a protective $\mathrm{T}_{\mathrm{H}} 1$ response in resistant hosts but induce suppressive adaptive immunity in susceptible hosts, which is probably mediated by infection-induced T-regulatory cells ${ }^{94}$. Our preliminary data suggest that a unique subset of inducible T-regulatory cells play a crucial part in mediating fatal disease in an animal model of disseminated, lethal SFG rickettsiosis. We are currently undertaking 


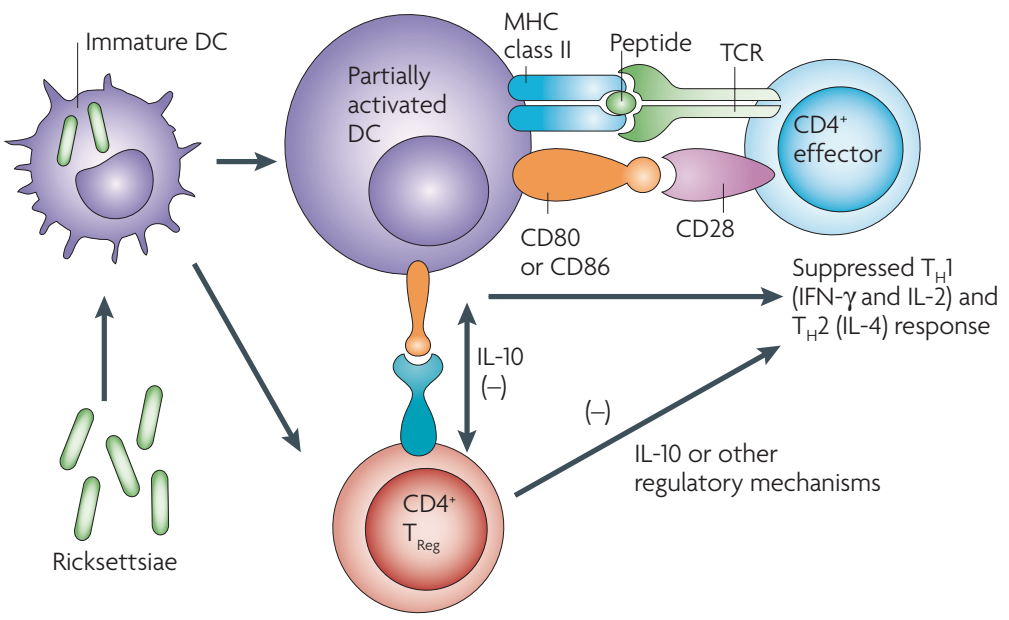

Figure 4 | Early interactions between rickettsiae and dendritic cells (DCs) and acquired immunity. Rickettsial infection stimulates partial DC maturation, as shown by the upregulation of major histocompatibility complex $(\mathrm{MHC})$ and co-stimulatory molecules. Bone-marrow-derived DCs from susceptible murine hosts that are infected in vitro with Rickettsia fail to stimulate Rickettsia-specific $\mathrm{CD}^{+} \mathrm{T}$-cell differentiation into $\mathrm{T}_{H} 1$ or $\mathrm{T}_{\mathrm{H}} 2$ cells that produce interferon- $\gamma$ (IFN- $\gamma$ ) or interleukin (IL)-4, respectively. Suppressed effects on $\mathrm{CD} 4^{+} \mathrm{T}$-cell responses are associated with IL-10 production by DCs as well as increased numbers of $C D 4^{+} \mathrm{CD} 25^{+}$Foxp $3^{-}{ }^{-}$-regulatory $\left(T_{\text {Reg }}\right)$ cells that also secrete IL-10. This process suggests that immune suppression is a mechanism that contributes to the development of progressive, fatal spotted-fever rickettsiosis.

several approaches to identify the immune regulatory mechanism (or mechanisms) by which T-regulatory cells mediate immune suppression in fatal SFG rickettsiosis. Taken together, studies of the early interaction between SFG Rickettsia spp. and DCs not only enhance our understanding of the cellular immune mechanisms that account for mild and severe rickettsial disease, but can also be used to help develop effective and optimal immunotherapeutic approaches that both enhance protective immunity and abrogate the immunosuppressive mechanisms that are responsible for fatal spotted-fever rickettsial diseases.

NK cells provide an early source of IFN- $\gamma$ in immune responses to species of Rickettsia (FIG. 3), with a significant expansion of NK cells occurring 2 days after rickettsial infection. Depletion of NK cells enhances the susceptibility of mice to $R$. conorii infection ${ }^{96}$. Enhanced $\mathrm{NK}$ activity during rickettsial infection is associated with high serum levels of IL-12 and IFN- $\gamma$ (FIG. 3), which suggests that NK cells have a role in mediating the protective $\mathrm{T}_{\mathrm{H}} 1$ response in anti-rickettsial immunity ${ }^{96}$. Current studies in our laboratory are directed towards analysing early DC-NK crosstalk in vitro and in vivo following sublethal and lethal rickettsial disease in the presence or absence of tick saliva. These studies could provide essential information that is necessary for molecular identification of rickettsial ligands or vaccine candidates that stimulate innate immune cells and protective specific immunity against Rickettsia spp.

Acquired immune response against Rickettsia spp. Animal models of disseminated rickettsiosis caused by intravenous $R$. conorii or $R$. australis infection in $\mathrm{C} 3 \mathrm{H} / \mathrm{HeN}$ or C57BL/6 mice, respectively, have revealed the crucial roles of T- and B-cell responses against rickettsiae (FIG. 3). Experiments with mice that were depleted of, or deficient in, particular subsets of cells or cytokines ${ }^{90,91,97}$ demonstrated that a deficiency of $\mathrm{CD}^{+} \mathrm{T}$ cells, IFN- $\gamma$ or TNF markedly increases the susceptibility of mice to infection with $R$. conorii. CD8 ${ }^{+} \mathrm{T}$ cells mediate their effector function against Rickettsia spp. through both IFN- $\gamma$ production and cytotoxic killing of infected target cells. In humans, perivascular infiltrates of $\mathrm{CD}^{+}$ and $\mathrm{CD} 4^{+} \mathrm{T}$ cells are present in skin lesions of patients with SFG rickettsiosis ${ }^{98}$. Depletion and adoptive-transfer experiments indicate that $\mathrm{CD}^{+} \mathrm{T}_{\mathrm{H}} 1$ cells mediate protective immunity against Rickettsia spp. through several pathways: the production of IFN- $\gamma$ and TNF, which activate microbicidal activities of infected target cells; Rickettsia-specific CD4 ${ }^{+} \mathrm{T}$-cell help to antigen-specific $B$ cells and therefore antibody production, an important host defence against re-infection; and $\mathrm{CD} 4^{+} \mathrm{T}$-cell help for the induction of cytotoxic CD8 ${ }^{+} \mathrm{T}$ cells, an indispensable component of protective cellular immunity against species of Rickettsia (FIG. 3). Polyclonal antibodies to $R$. conorii and monoclonal antibodies to OmpA and OmpB provide effective passive immunity in infected severe combined immunodeficient mice ${ }^{66}$. This antibody-mediated protection is Fc-dependent, suggesting that antibodies have a role in opsonization and phagocytosis of extracellular rickettsiae. Interestingly, polyclonal antibodies and an anti-OmpB monoclonal antibody inhibit the escape of $R$. conorii from the phagosome of endothelial cells or macrophages, which results in phagolysosomal killing through nitric oxide, reactive oxygen intermediates and L-tryptophan starvation ${ }^{99}$. These observations suggest that anti-rickettsial antibodies, including anti-OmpB, neutralize an antigenic determinant on a rickettsial protein that plays a part in the escape of rickettsiae to the cytosol. Similar to SFG rickettsiae, the immune reactivity and immunogenicity of R. typhi and R. prowazekii OmpB have been characterized in an attempt to identify synthetic antigens that can be used in specific diagnostic immunoassays or candidate vaccines. These studies show that $R$. typhi and $R$. prowazekii OmpB are indeed immune reactive and immunogenic as measured by the ability of purified OmpB from R. typhi or R. prowazekii (Madrid E and Breinl strains, respectively) to induce strong proliferation and IFN- $\gamma$ production in vitro through human $\mathrm{CD} 4^{+}$ $\mathrm{T}$-cell clones from individuals who are seropositive for R. $t y p h i^{100}$ and the ability of purified OmpB of $R$. typhi to stimulate humoral and cell-mediated immune responses in guinea pigs and mice ${ }^{101,102}$. The antibody-binding sites and linear peptide epitopes on these proteins were characterized ${ }^{102}$. However, the limited numbers and weak immune reactivity of these linear peptide epitopes against patient sera suggest that they are not useful for diagnosis. Yet these studies do not exclude the possibility that conformational epitopes of OmpB or other outermembrane or cytoplasmic proteins of SFG or typhusgroup rickettsiae play an important part in protection. In support of this possibility is the recent finding that immunization with avirulent $R$. rickettsii str. Iowa that is 


\section{Box 3 | Genomics}

Rickettsiae have undergone dramatic genome reduction $(1.1-1.3 \mathrm{Mb}$ ) by relying on the host for the synthesis of many amino acids and nucleotides ${ }^{109}$. The rickettsiae have a close evolutionary relationship with the ancestor of mitochondria ${ }^{110,111}$. The genomes of seven Rickettsiaceae have been sequenced and annotated ${ }^{23,24,111-113}$. The Rickettsia bellii and Rickettsia canadensis genomes exhibit little synteny with spotted-fever-group or typhus-group rickettsiae, which suggests that these species may have retained ancestral features that were lost from other lineages in the course of evolution ${ }^{4,23,24}$. Plasmid sequences have recently been identified in Rickettsia felis, R. bellii, Rickettsia monacensis, Rickettsia amblyomii, Rickettsia helvetica, Rickettsia peacockii and Rickettsia massiliae, some of which are integrated into the chromosome ${ }^{4,113-115}$. Rickettsia species contain many pseudogenes, which are segments of DNA that do not produce a functional protein ${ }^{23,116}$. For example, both Rickettsia prowazekii and Rickettsia conorii contain intact genes that mediate the formation of succinate dehydrogenase, nicotinamide adenine dinucleotide (NADH), cytochrome reductase and cytochrome oxidase ${ }^{23}$. However, these genes are absent from Rickettsia typhi. Similarly, both $R$. prowazekii and $R$. conorii contain the genes coxABC and cydAB, which encode a putative cytochrome $c$ oxidase and cytochrome $d$ ubiquinol oxidase, respectively ${ }^{23,111,112,117}$ — monomeric proteins that are used for aerobic respiration under differing oxygen concentrations. However, it has been shown that $R$. typhi has only one terminal oxidase for aerobic respiration of the cytochrome $d$ type, which is usually expressed during stress conditions, such as low-oxygen concentration ${ }^{23,117}$. The presence of these pseudogenes might explain the different clinical manifestations and disease severities that are caused by human infection with $R$. typhi compared with those caused by $R$. prowazekii and $R$. conorii. the identification of virulence genes and elucidation of their effect on the host. Thus, although rickettsial research has generated a wealth of data, we still lack crucial information that is directly relevant to human disease and can be effectively applied towards vaccines and immunotherapy.

Examples of the gaps in our knowledge include: the crucial rickettsial virulence factor (or factors) that mediates immune evasion or modulation and intracellular survival; the immunodominant and subdominant T-cell epitopes that mediate protective immunity against species of Rickettsia; and the functions of rickettsial genes that have been annotated without experimental analysis. The exact pathophysiological and immune mechanism (or mechanisms) that accounts for host resistance or susceptibility to virulent Rickettsia species, such as $R$. rickettsii and $R$. conorii, or accounts for mild disease following infection with less-virulent rickettsial species; the microbial or host-related regulatory mechanisms that abrogate or enhance tissue injury and progression of the disease; and the mechanisms that control the induction of these regulatory mechanisms also remain unknown. Furthermore, the effect of variables such as infectious dose, route of infection and host genetic susceptibility on host defence against Rickettsia species; the immunomodulatory effects of tick saliva at the site of inoculation; the course and route of rickettsial spread from the skin; the mechanism and importance of rickettsial-infection-associated immunosuppression; and the mechanism of perivascular emigration of immune $\mathrm{CD}^{+}$and $\mathrm{CD}^{+} \mathrm{T}$ lymphocytes and macrophages at the site of microvascular infection require further elucidation.

More importantly, what is the relevance of these in vitro studies and in vivo animal studies to humans, taking into consideration important factors such as age, gender, genetic polymorphisms, immune status, preexisting morbidity and risk factors, such as diabetes and alcoholism. Future progress is required to identify the complete set of rickettsial adhesins and host cell receptors, the importance of Rickettsia-induced oxidative stress on endothelial cells in vivo and other mechanisms of cell and tissue injury in rickettsial diseases. A reliable genetic system is needed for inactivation of rickettsial genes to attribute functions to putative virulence factors, including phospholipase $\mathrm{D}$, haemolysin $\mathrm{C}$ and RickA (TABLE 2). The contributions of cytokines, cytotoxic T lymphocytes and T-regulatory cells to the pathogenesis of tissue injury in rickettsial infection also need to be further determined. To understand the mechanisms of the most important pathophysiological mechanisms in rickettsioses, the relative roles of oxidative stress, pro-inflammatory cytokines, vascular endothelial growth factor and other factors should be analysed. For vaccine development, it is important to identify the immunodominant rickettsial antigens that stimulate $\mathrm{CD}^{+}$and $\mathrm{CD}^{+}{ }^{+} \mathrm{T}$ lymphocytes to secrete protective cytokines, stimulate protective antibodies, in addition to anti-OmpA and anti-OmpB, and stimulate cytotoxic $\mathrm{CD}^{+} \mathrm{T}$ lymphocytes that eliminate rickettsiae-infected endothelial cells. 
1. Walker, D. H. Rickettsiae and rickettsial infections: the current state of knowledge. Clin. Infect. Dis. $\mathbf{4 5}$ (Suppl. 1), 39-44 (2007)

2. Yu, X. J. \& Walker, D. H. in Bergey's Manual of Systematic Bacteriology 2nd edn Vol. 2 (eds Brenner, D. J., Kreig, N. R. \& Staley, J. T.) 96-116 (Springer, New York, 2005)

3. Azad, A. F. \& Beard, C. B. Rickettsial pathogens and their arthropod vectors. Emerg. Infect. Dis. $\mathbf{4}$ 179-186 (1998)

4. Gillespie, J. J. et al. Plasmids and rickettsial evolution: insight from Rickettsia felis. PloS One 2, e266 (2007).

5. Ricketts, H. T. The study of "Rocky Mountain spotted fever" (tick fever?) by means of animal inoculations. JAMA 47, 33-36 (1906).

6. Walker, D. H. Rocky Mountain spotted fever: a disease in need of microbiological concern. Clin. Microbiol. Rev. 2, 227-240 (1989).

7. Parola, P., Paddock, C. D. \& Raoult, D. Tick-borne rickettsioses around the world: emerging diseases challenging old concepts. Clin. Microbiol. Rev. 4 719-756 (2005)

8. Jensenius, M., Fournier, P. E., Kelly, P., Myrvang, B. \& Raoult, D. African tick bite fever. Lancet Infect. Dis. 3 557-564 (2003)

9. Raoult, D. et al. Rickettsia africae, a tick-borne pathogen in travelers to sub-Saharan Africa. N. Engl. J. Med. 344, 1504-1510 (2001).

10. Parker, R. R. in Proc. 3rd Int. Congr. Microbiol. 390-391 (1940)

11. Paddock, C. D. et al. Rickettsia parkeri: a newly recognized cause of spotted fever rickettsiosis in the United States. Clin. Infect. Dis. 38, 805-811 (2004).

12. Lakos, A. Tick-borne lymphadenopathy - a new rickettsial disease? Lancet 350, 1006-1008 (1997)

13. Oteo, J. A. et al. Dermacentor-borne necrosis erythema and lymphadenopathy: clinical and epidemiological features of a new tick-borne disease. Clin. Microbiol. Infect. 10, 327-331 (2004).

14. Fournier, P. E., Gouriet, F., Brouqui, P., Lucht, F. \& Raoult, D. Lymphangitis-associated rickettsiosis, a new rickettsiosis caused by Rickettsia sibirica mongolotimonae: seven new cases and review of the literature. Clin. Infect. Dis. 40, 1435-1444 (2005).

15. Stenos, J., Roux, V., Walker, D. H. \& Raoult, D. Rickettsia honei sp. nov., the aetiologic agent of Flinders Island spotted fever in Australia. Int. J. Syst. Bacteriol. 48, 1399-1404 (1998).

16. Uchida, T., Uchiyama, T., Kumano, K. \& Walker, D. H. Rickettsia japonica sp. nov., the etiological agent of spotted fever group rickettsiosis in Japan. Int. J. Syst. Bacteriol. 42, 303-305 (1992).

17. Mahara, F. Japanese spotted fever: report of 31 cases and review of the literature. Emerg. Infect. Dis. 3 105-111 (1997)

18. Burgdorfer, W. et al. Rhipicephalus sanguineus: vector of a new spotted fever group rickettsia in the United States. Infect. Immun. 12, 205-210 (1975).

19. Niebylski, M. L. et al. Rickettsia peacockii sp. nov., a new species infecting wood ticks, Dermacentor andersoni, in western Montana. Int. J. Syst. Bacteriol. 47, 446-452 (1997)

20. Bozeman, F. M., Masiello, S. A., Williams, M. S. \& Elisberg, B. L. Epidemic typhus rickettsiae isolated from flying squirrels. Nature 255, 545-547 (1975).

21. Azad, A. F. Pathogenic rickettsiae as bioterrorism agents. Clin. Infect. Dis. 45 (Suppl. 1), 52-55 (2007).

22. Raoult, D. et al. Outbreak of epidemic typhus associated with trench fever in Burundi. Lancet 352 353-358 (1998)

23. McLeod, M. P. et al. Complete genome sequence of Rickettsia typhi and comparison with sequences of other rickettsiae. J. Bacteriol. 186, 5842-5855 (2004).

An annotation of the genome of $R$. typhi that built on the previously sequenced Rickettsia spp. genomes to provide a picture of Rickettsia functional diversity.

24. Ogata, H. et al. Genome sequence of Rickettsia bellii illuminates the role of amoebae in gene exchanges between intracellular pathogens. PLoS Genet. 2, e76 (2006).

25. McKiel, Y. A., Bell, E. J. \& Lackman, D. B. Rickettsia canada: a new member of the typhus group of rickettsiae isolated from Haemaphysalis leporispalustris ticks in Canada. Can. J. Microbiol. 13 503-510 (1967)

26. Paddock, C. D. et al. Isolation of Rickettsia akari from eschars of patients with rickettsialpox. Am. J. Trop. Med. Hyg. 75, 732-738 (2006).
27. Andrew, R., Bonin, J. M. \& Williams, S. Tick typhus in North Queensland. Med. J. Aust. 2, 253-258 (1946)

28. Bouyer, D. H. et al. Rickettsia felis: molecular characterization of a new member of the spotted fever group. Int. J. Syst. Evol. Microbiol. 51, 339-347 (2001).

29. Dumler, J. S. \& Walker, D. H. Rocky Mountain spotted fever - changing ecology and persisting virulence. N. Engl. J. Med. 353, 551-553 (2005).

30. Dantas-Torres, F. Rocky Mountain spotted fever. Lancet Infect. Dis. 7, 724-732 (2007).

31. Walker, D. H., Occhino, C., Tringali, G. R., Di Rosa, S. \& Mansueto, S. Pathogenesis of rickettsial eschars: the tache noire of boutonneuse fever. Hum. Pathol. 19, 1449-1454 (1988)

32. Kaplowitz, L. G., Fischer, J. J. \& Sparling, P. F. Rocky Mountain spotted fever: a clinical dilemma. Curr. Clin. Top. Infect. Dis. 2, 89-108 (1981).

33. Walker, D. H. \& Raoult, D. in Principles and Practice of Infectious Diseases 6th edn (eds Mandell, G. L., Bennett, J. E. \& Dolin, R.) 2287-2295 (Churchill Livingstone, New York, 2004)

34. Zinsser, H. Rats, Lice and History 3-301 (Little, Brown and Company, Boston, 1935).

35. Brill, N. E. An acute infectious disease of unknown origin: a clinical study based on 221 cases. $\mathrm{Am}$. J. Med. Sci. 139, 484-502 (1910).

36. Zinsser, H. \& Castaneda, M. R. On the isolation from a case of Brill's disease of a typhus strain resembling the European type. N. Engl. J. Med. 209, 815-819 (1933).

37. Biological and chemical terrorism: strategic plan for preparedness and response; recommendations of the CDC Strategic Planning Workgroup. MMWR 49,1-14 (2000)

38. Alibek, K. \& Handelman, S. Biohazard 3-319 (Random House, New York, 1999).

39. Reynolds, M. G. et al. Flying squirrel-associated typhus, United States. Emerg. Infect. Dis. 9 1341-1343 (2003)

40. Medina-Sanchez, A. et al. Detection of a typhus group Rickettsia in Amblyomma ticks in the state of Nuevo Leon, Mexico. Ann. NY Acad. Sci. 1063, 327-332 (2005).

41. Reiss-Gutfreund, R. J. The isolation of Rickettsia prowazekii and mooseri from unusual sources. Am. J. Trop. Med. Hyg. 15, 943-950 (1966).

42. Burgdorfer, W., Hayes, S. F. \& Mavros, A. J. in Rickettsiae and Rickettsial Diseases (eds Burgdorfer, W. \& Anacker, R. L.) 585-594 (Academic, New York, 1981).

43. Macaluso, K. R., Sonenshine, D. E., Ceraul, S. M. \& Azad, A. F. Rickettsial infection in Dermacentor variabilis (Acari: Ixodidae) inhibits transovarial transmission of a second Rickettsia. J. Med. Entomol. 39, 809-813 (2002).

44. Parker, R. R. \& Spencer, R. R. Rocky Mountain spotted fever: a study of the relationship between the presence of rickettsia-like organisms in tick smears and infectiveness of the same ticks. Public Health Rep. 41, 461-469 (1926)

45. Burgdorfer, W. in Biology of Rickettsial Diseases (ed. Walker, D. H.) 33-50 (CRC, Boca Raton, 1988).

46. Niebylski, M. L., Peacock, M. G. \& Schwan, T. G. Lethal effect of Rickettsia rickettsii on its tick vector (Dermacentor andersoni). Appl. Environ. Microbiol. 65, 773-778 (1999).

First experimental proof that virulent Rickettsia spp. are pathogenic for their tick hosts, which revealed that rickettsial evolution of virulence has costs for both vertebrate and invertebrate hosts.

47. Walker, D. H., Harrison, A., Henderson, F. \& Murphy, F. A. Identification of Rickettsia rickettsii in a guinea pig model by immunofluorescent and electron microscopic techniques. Am. J. Pathol. 86, 343-358 (1977).

48. Hayes, S. F. \& Burgdorfer, W. Reactivation of Rickettsia rickettsii in Dermacentor andersoni ticks: an ultrastructural analysis. Infect. Immun. 37, 779-785 (1982)

49. Kotsyfakis, M. et al. Anti-inflammatory and immunosuppressive activity of sialostatin L, a salivary cystatin from the tick Ixodes scapularis. J. Biol. Chem. 281, 26298-26307 (2006).

50. Brossard, M. \& Wikel, S. K. Tick immunobiology. Parasitology 129, S161-S176 (2004).

51. Valenzuela, J. G. Exploring tick saliva: from biochemistry to "sialomes" and functional genomics. Parasitology 129, S83-S94 (2004).
52 Montgomery, R. R., Lusitani, D., De Boisfleury Chevance, A. \& Malawista, S. E. Tick saliva reduces adherence and area of human neutrophils. Infect. Immun. 72, 2989-2994 (2004).

53. Kovar, L. Tick saliva in anti-tick immunity and pathogen transmission. Folia Microbiol. 49, 327-332 (2004).

54. Kubes, M., Fuchsberger, N., Labuda, M., Zuffova, E. \& Nuttall, P. A. Salivary gland extracts of partially fed Dermacentor reticulatus ticks decrease natural killer cell activity in vitro. Immunology 82, 113-116 (1994).

55. Gillespie, R. D., Dolan, M. C., Piesman, J. \& Titus, R. G. Identification of an IL-2 binding protein in the saliva of the Lyme disease vector tick, Ixodes scapularis. J. Immunol. 166, 4319-4326 (2001)

56. Ferreira, B. R. \& Silva, J. S. Successive tick infestations selectively promote a T-helper 2 cytokine profile in mice. Immunology 96, 434-439 (1999).

57. Mejri, N. \& Brossard, M. Splenic dendritic cells pulsed with Ixodes ricinus tick saliva prime naive CD4 ${ }^{+} T$ to induce $\mathrm{T}_{\mathrm{h}} 2$ cell differentiation in vitro and in vivo. Int. Immunol. 19, 535-543 (2007)

58. Cavassani, K. A., Aliberti, J. C., Dias, A. R., Silva, J. S \& Ferreira, B. R. Tick saliva inhibits differentiation, maturation and function of murine bone-marrow-derived dendritic cells. Immunology 114, 235-245 (2005).

59. Sa-Nunes, A. et al. Prostaglandin E2 is a major inhibitor of dendritic cell maturation and function in Ixodes scapularis saliva. J. Immunol. 179 , 1497-1505 (2007).

60. Martinez, J. J., Seveau, S., Veiga, E., Matsuyama, S. \& Cossart, P. Ku70, a component of DNA-dependent protein kinase, is a mammalian receptor for Rickettsia conorii. Cell 123, 1013-1023 (2005).

The first paper to identify the Ku70 subunit of DNA-dependent protein kinase as a cell-surface receptor that is used by spotted-fever-group rickettsiae to enter non-phagocytic cells. Also identified the rickettsial protein OmpB as a ligand for Ku70.

61. Ramm, L. E. \& Winkler, H. H. Identification of cholesterol in the receptor site for rickettsiae on sheep erythrocyte membranes. Infect. Immun. 13, 120-126 (1976).

62. Martinez, J. J. \& Cossart, P. Early signaling events involved in the entry of Rickettsia conorii into mammalian cells. J. Cell Sci. 117, 5097-5106 (2004)

63. Monferran, S. et al. The membrane-associated form of the DNA repair protein $\mathrm{Ku}$ is involved in cell adhesion to fibronectin. J. Mol. Biol. 337, 503-511 (2004).

64. Hackstadt, T., Messer, R., Cieplak, W. \& Peacock, M. G. Evidence for proteolytic cleavage of the 120-kilodalton outer membrane protein of rickettsiae identification of an avirulent mutant deficient in processing. Infect. Immun. 60, 159-165 (1992).

65. Crocquet-Valdes, P. A. et al. Immunization with a portion of rickettsial outer membrane protein A stimulates protective immunity against spotted fever rickettsiosis. Vaccine 20, 979-988 (2001).

66. Feng, H. M., Whitworth, T., Olano, J. P., Popov, V. L. \& Walker, D. H. Fc-dependent polyclonal antibodies and antibodies to outer membrane proteins $\mathrm{A}$ and $\mathrm{B}$, but not to lipopolysaccharide, protect SCID mice against fatal Rickettsia conorii infection. Infect. Immun. 72 2222-2228 (2004).

Surprisingly, the long-standing emphasis on the importance of cell-mediated immunity for the clearance of rickettsiae and recovery from infection had missed the important concept for vaccine development that the presence of antibodies to epitopes of the outer-membrane proteins A and B prevents illness.

67. Uchiyama, T., Kawano, H. \& Kusuhara, Y. The major outer membrane protein rOmpB of spotted fever group rickettsiae functions in the rickettsial adherence to and invasion of Vero cells. Microbes Infect. $\mathbf{8}$ 801-809 (2006)

68. Li, H. \& Walker, D. H. rOmpA is a critical protein for the adhesion of Rickettsia rickettsii to host cells. Microb. Pathog. 24, 289-298 (1998).

69. Jensenius, M. et al. Systemic inflammatory responses in African tick-bite fever. J. Infect. Dis. 187, 1332-1336 (2003).

70. Elghetany, M. T. \& Walker, D. H. Hemostatic changes in Rocky Mountain spotted fever and Mediterranean spotted fever. Am. J. Clin. Pathol. 112, 159-168 (1999).

71. Teysseire, N., Arnoux, D. I., George, F., Sampol, J. \& Raoult, D. von Willebrand factor release and 
thrombomodulin and tissue factor expression in Rickettsia conorii-infected endothelial cells. Infect. Immun. 60, 4388-4393 (1992)

72. Sporn, L. A. \& Marder, V. J. Interleukin- $1 \alpha$ production during Rickettsia rickettsii infection of cultured endothelial cells: potential role in autocrine cell stimulation. Infect. Immun. 64, 1609-1613 (1996).

73. Shi, R.-J., Simpson-Haidaris, P. J., Marder, V. J., Silverman, D. J. \& Sporn, L. A. Increased expression of plasminogen activator inhibitor-1 in $R$. rickettsiiinfected endothelial cells. Thromb. Haemost. $\mathbf{7 5}$ 600-606 (1996)

74. Oristrell, J., Sampere, M., Amengual, M. J., Font, B. \& Segura, F. Plasma interleukin-6 levels in Mediterranean spotted fever. Eur. J. Clin. Microbiol. Infect. Dis. 23, 417-418 (2004).

75. Rydkina, E., Sahni, A., Baggs, R. B., Silverman, D. J. \& Sahni, S. K. Infection of human endothelial cells with spotted fever group rickettsiae stimulates cyclooxygenase 2 expression and release of vasoactive prostaglandins. Infect. Immun. 74, 5067-5074 (2006).

76. Walker, T. S., Brown, J. S., Hoover, C. S. \& Morgan, D. A. Endothelial prostaglandin secretion: effects of typhus rickettsiae. J. Infect. Dis.162, 1136-1144 (1990).

77. Rydkina, E., Sahni, A., Silverman, D. J. \& Sahni, S. K. Rickettsia rickettsii infection of cultured human endothelial cells induces heme oxygenase 1 expression. Infect. Immun. 70, 4045-4052 (2002).

78. Woods, M. E. \& Olano, J. P. Host defenses to Rickettsia rickettsii infection contribute to increased microvascular permeability in human cerebral endothelial cells. J. Clin. Immunol. 28, 174-185 (2008).

The most important pathophysiological effect of rickettsial disease, increased vascular permeability, was addressed mechanistically, which revealed the likelihood of cytokine contribution to pathology.

79. Clifton, D. R. et al. NF-kB-dependent inhibition of apoptosis is essential for host cell survival during Rickettsia rickettsii infection. Proc. Natl Acad. Sci. USA 95, 4646-4651 (1998).

80. Clifton, D. R., Rydkina, E., Freeman, R. S. \& Sahni, S. K. NF-kB activation during Rickettsia rickettsii infection of endothelial cells involves the activation of catalytic IKB kinases IKK $\alpha$ and IKK $\beta$ and phosphorylation-proteolysis of the inhibitor protein IкB $\alpha$. Infect. Immun. 73, 155-165 (2005).

81. Valbuena, G., Bradford, W. \& Walker, D. H. Expression analysis of the T-cell-targeting chemokines CXCL9 and CXCL10 in mice and humans with endothelial infections caused by rickettsiae of the spotted fever group. Am. J. Pathol. 163, 1357-1369 (2003).

82. Valbuena, G. \& Walker, D. H. Expression of CX3CL1 (fractalkine) in mice with endothelial-target rickettsial infection of the spotted-fever group. Virchows Archiv. 446, 21-27 (2004).

83. Whitworth, T., Popov, V. L., Yu, X. J., Walker, D. H. \& Bouyer, D. H. Expression of the Rickettsia prowazekii pld or tlyC gene in Salmonella enterica serovar Typhimurium mediates phagosomal escape. Infect. Immun. 73, 6668-6673 (2005)

84. Monack, D. M. \& Theriot, J. A. Actin-based motility is sufficient for bacterial membrane protrusion formation and host cell uptake. Cell. Microbiol. 3, 633-647 (2001).

85. Heinzen, R. A., Grieshaber, S. S., Van Kirk, L. S. $\delta$ Devin, C. J. Dynamics of actin-based movement by Rickettsia rickettsii in Vero cells. Infect. Immun. 67, 4201-4207 (1999).

86. Van Kirk, L. S., Hayes, S. F. \& Heinzen, R. A. Ultrastructure of Rickettsia rickettsii actin tails and localization of cytoskeletal proteins. Infect. Immun. 68, 4706-4713 (2000).

87. Gouin, E. et al. The RickA protein of Rickettsia conoril activates the Arp2/3 complex. Nature 427, 457-46 (2004).

Rickettsial actin-based mobility was shown to be associated with the activation of Arp $2 / 3$ by Rick A a protein of the spotted-fever-group rickettsiae.

88. Jeng, R. L. et al. A Rickettsia WASP-like protein activates the Arp2/3 complex and mediates actinbased motility. Cell. Microbiol. 6, 761-769 (2004).

89. Simser, J. A., Rahman, M. S., Dreher-Lesnick, S. M. \& Azad, A. F. A novel and naturally occurring transposon, ISRpe 1 in the Rickettsia peacocki genome disrupting the rickA gene involved in actinbased motility. Mol. Microbiol. 58, 71-79 (2005).

90. Feng, H. M., Popov, V. L. \& Walker, D. H. Depletion of gamma interferon and tumor necrosis factor alpha in mice with Rickettsia conorii-infected endothelium: impairment of rickettsicidal nitric oxide production resulting in fatal, overwhelming rickettsial disease. Infect. Immun. 62, 1952-1960 (1994).

91. Walker, D. H., Olano, J. P. \& Feng, H. M. Critical role of cytotoxic T lymphocytes in immune clearance of rickettsial infection. Infect. Immun. 69, 1841-1846 (2001)

Revealed that recovery from rickettsial infection requires the $\mathrm{CD}^{+}{ }^{+} \mathrm{T}$ lymphocyte cytotoxic response.

92. Sousa, R. et al. Intralesional expression of mRNA of interferon- $\gamma$, tumour necrosis factor- $\alpha$, interleukin- 10 nitric oxide synthase, indoleamine-2,3-dioxygenase, and RANTES is a major immune effector in Mediterranean spotted fever rickettsiosis. J. Infect. Dis. 196, 770-781 (2007)

The important immune effectors in rickettsial infections of mice were demonstrated to be present in lesions of human patients with Mediterranean spotted fever.

93. Feng, H. M. $\&$ Walker, D. H. Mechanisms of intracellular killing of Rickettsia conorii in infected human endothelial cells, hepatocytes, and macrophages. Infect. Immun. 68, 6729-6736 (2000).

Rickettsicidal mechanisms that are important in intracellular killing in mice - nitric oxide, reactive oxygen species and tryptophan limitation - were demonstrated to be effectors in human target cells.

94. Fang, R. et al. Differential interaction of dendritic cells with Rickettsia: impact on host susceptibility to murine spotted fever rickettsiosis. Infect. Immun. 75 3112-3123 (2007)

95. Jordan, J. M., Woods, M. E., Feng, H.-M., Soong, L. \& Walker, D. H. Rickettsiae-stimulated dendritic cells mediate protection against lethal rickettsial challenge in an animal model of spotted fever rickettsiosis. J. Infect. Dis. 196, 629-638 (2007).

Revealed that DCs play crucial parts in innate and adaptive immunity to Rickettsia spp.

96. Billings, A. N., Feng, H. M., Olano, J. P. \& Walker, D. H. Rickettsial infection in murine models activates an early anti-rickettsial effect mediated by NK cells and associated with production of gamma interferon. Am. J. Trop. Med. Hyg. 65, 52-56 (2001).

97. Feng, H. M., Popov, V. L., Yuoh, G. \& Walker, D. H. Role of T lymphocyte subsets in immunity to spotted fever group rickettsiae. J. Immunol. 158, 5314-5320 (1997).

98. Herrero-Herrero, J. I., Walker, D. H. \& Ruiz-Beltran, R. Immunohistochemical evaluation of the cellular mmune response to Rickettsia conorii in taches noires. J. Infect. Dis. 155, 802-805 (1987).

99. Feng, H. M., Whitworth, T., Popov, V. L. \& Walker D. H. Effect of antibody on the rickettsia-host cell interaction. Infect. Immun. 72, 3524-3530 (2004).

100. Carl, M. et al. Heterogeneity of CD4-positive human T-cell clones which recognize the surface protein antigen of Rickettsia typhi. Infect. Immun. $\mathbf{5 7}$. 1276-1280 (1989).

101. Ching, W. M., Carl, M. \& Dasch, G. A. Mapping of monoclonal antibody binding sites on $\mathrm{CNBr}$ fragments of the S-layer protein antigens of Rickettsia typhi and Rickettsia prowazekii. Mol. Immunol. 29, 95-105 (1992)

102. Ching, W. M., Wang, H., Jan, B. \& Dasch, G. A. Identification and characterization of epitopes on the 120-kilodalton surface protein antigen of Rickettsia prowazekii with synthetic peptides. Infect. Immun. 64 1413-1419 (1996)

103. Ellison, D. W. et al. Genomic comparison of virulent Rickettsia rickettsii Sheila Smith and avirulent Rickettsia rickettsii lowa. Infect. Immun. 76, 542-550 (2008).

104. Sumner, J. W. Sims, K. G., Jones, D. C. \& Anderson, B. E. Protection of guinea-pigs from experimental Rocky Mountain spotted fever by immunization with baculovirus-expressed Rickettsia rickettsii rOmpA protein. Vaccine 13, 29-35 (1995).

Showed that outer-membrane protein A is an antigen that stimulates protective immunity to $R$. rickettsii, and thus is an excellent candidate for incorporation into a protective vaccine against SFG rickettsiae.

105. Bourgeois, A. L. \& Dasch, G. A. in Rickettsiae and Rickettsial Diseases (eds Burgdorfer, W. \& Anacker, R. L.) 71-80 (Academic, New York, 1981) Showed that outer-membrane protein B is an antigen that stimulates protective immunity to $R$. typhi, and thus is an excellent candidate for incorporation into vaccines against all Rickettsia spp.
106. Valbuena, G., Jordan, J. M., Walker, D. H. T cells mediate cross-protective immunity between spotted fever group rickettsiae and typhus group rickettsiae. J. Infect. Dis. 190, 1221-1227 (2004). Divergent Rickettsia spp. of the typhus and spotted-fever groups that generally do not stimulate even cross-reactive antibodies were shown to contain antigens that stimulate T lymphocytes, which mediate cross-protection.

107. Vitorino, L., Chelo, I. M., Bacellar, F. \& Ze-Ze, L. Rickettsial phylogeny: a multigenic approach. Microbiology 153, 160-168 (2007).

108. Gevers, D. et al. Re-evaluating prokaryotic species. Nature Rev. Microbiol. 3, 733-739 (2005).

19. Andersson, J. O. \& Andersson, S. G. Insights into the evolutionary process of genome degradation. Curr. Opin. Genet. Dev. 9, 664-671 (1999).

110. Andersson, S. G. \& Kurland, C. G. Origins of mitochondria and hydrogenosomes. Curr. Opin. Microbiol. 2, 535-541 (1999).

111. Andersson, S. G. et al. The genome sequence of Rickettsia prowazekii and the origin of mitochondria. Nature 396, 133-140 (1998)

112. Ogata, H. et al. Mechanisms of evolution in Rickettsia conorii and R. prowazekii. Science 293, 2093-2098 (2001).

113. Ogata, H., Renesto, P., Audic, S., Robert, C. \& Blanc, G. The genome sequence of Rickettsia felis identifies the first putative conjugative plasmid in an obligate intracellular parasite. PLoS Biol. 3, e248 (2005).

114. Baldridge, G. D., Burkhardt, N. Y., Felsheim, R. F., Kurtti, T. J. \& Munderloh, U. G. Transposon insertion reveals pRM, a plasmid of Rickettsia monacensis. Appl. Environ. Microbiol. 73, 4984-4995 (2007).

115. Baldridge, G. D., Burkhardt, N. Y., Felsheim, R. F Kurtti, T. J. \& Munderloh, U. G. Plasmids of the pRM/ pRF family occur in diverse Rickettsia species. Appl. Environ. Microbiol. 74, 645-652 (2008).

116. Andersson, J. O. \& Andersson, S. G. Pseudogenes, junk DNA, and the dynamics of Rickettsia genomes. Mol. Biol. Evol. 18, 829-839 (2001)

117. Kana, B. D. et al. Characterization of the $C y d A B$ encoded cytochrome $b d$ oxidase from Mycobacterium smegmatis. J. Bacteriol. 183 7076-7086 (2001).

118. Renesto, P. et al. Identification and characterization of a phospholipase D-superfamily gene in rickettsiae. J. Infect. Dis. 188, 1276-1283 (2003)

A potentially important virulence factor of pathogenic rickettsiae, phospholipase $D$, was identified and characterized functionally.

119. Gaywee, J., Xu, W., Radulovic, S., Bessman, M. J. \& Azad, A. F. The Rickettsia prowazekii invasion gene homolog (invA) encodes a nudix hydrolase active on adenosine (5')-pentaphospho-(5')-adenosine. Mol. Cell. Proteomics 1, 179-185 (2002)

120. Gaywee, J., Radulovic, S., Higgins, J. A. \& Azad, A. F. Transcriptional analysis of Rickettsia prowazekii invasion gene homolog (invA) during host cell infection. Infect. Immun. 70, 6346-6354 (2002)

121. Ngwamidiba, M., Blanc, G., Raoult, D. \& Fournier, P. E. Sca 1, a previously undescribed paralog from autotransporter protein-encoding genes in Rickettsia species. BMC Microbiol. 6, 12 (2006).

122. Ogawa, M. et al. Proteome analysis of Rickettsia felis highlights the expression profile of intracellular bacteria. Proteomics 7, 1232-1248 (2007).

123. Burns, D. L. Type IV transporters of pathogenic bacteria. Curr. Opin. Microbiol. 6, 29-34 (2003).

\section{Acknowledgements}

The authors thank D. Baker for expert secretarial contribu tions.

\section{DATABASES}

Entrez Genome Project: http://www.ncbi.nlm.nih.gov/ entrez/query.fcgi?db=genomepri Listeria monocytogenes | Rickettsia africae | Rickettsia akari Rickettsia bellii| Rickettsia canadensis $\mid$ Rickettsia conorii Rickettsia felis $\mid$ Rickettsia prowazekii $\mid$ Rickettsia rickettsii st lowa | Rickettsia rickettsii str. Sheila Smith | Rickettsia sibirica Rickettsia slovaca | Rickettsia typh

FURTHER INFORMATION

CDC emergency preparedness and response: bioterrorism agents and diseases (by category): http://www.bt.cdc.gov/ agent/agentlist-category

ALL LINKS ARE ACTIVE IN THE ONLINE PDF 